\title{
Prospective survey of use of therapeutic drugs, alcohol, and cigarettes during pregnancy
}

\author{
PETER C RUBIN, GILLIAN F CRAIG, KAREN GAVIN, DAVID SUMNER
}

\begin{abstract}
Use of drugs during pregnancy was recorded prospectively in 2765 women attending the antenatal clinics of a general hospital from October 1982 to March 1984. Of these women, $2588(93.6 \%)$ avoided exposure to drugs during the first trimester, $1802(65 \cdot 2 \%)$ took no drugs at any stage, $963(34.8 \%)$ took a total of 154 different drugs from 35 groups of drugs, and $243(8.8 \%)$ took a self administered drug. The most commonly used drugs were non-narcotic analgesics, usually self administered, and antibacterials. The last survey of use of drugs in pregnancy in the United Kingdom 20 years ago showed fewer women avoiding drugs throughout pregnancy (195 of $911(21.4 \%), p<0.001)$ and in the first trimester $(685(75.2 \%), p<0.001)$ and many more women taking a self administered drug (586 (64.4\%), $p<0.001)$ than at present.
\end{abstract}

Most women nowadays abstain totally from alcohol (1786 $(64.6 \%) v 109(12.0 \%)$ previously, $\mathrm{p}<0.001)$, but while more women are non-smokers compared with previously $(1811(65 \cdot 5 \%)$ $v 392(43 \%), p<0.001)$ the trend has been far less dramatic than that for use of alcohol.

\section{Introduction}

The thalidomide disaster and its ensuing publicity taught both the medical profession and the public that a drug taken by the mother could harm her developing baby. ${ }^{2}$ Several large studies performed in the early to mid-1960s after thalidomide, however, suggested that prescribed or self administered drugs were still being extensively used during pregnancy in Sweden, ${ }^{3}$ the United Kingdom, ${ }^{4}$ and the United States. $^{56}$ The only large survey performed since that time concerned recipients of Medicaid in Tennessee during the mid-1970s and suggested a continued high level of use during pregnancy.' We present here the findings of a prospective survey of exposure to drugs in an obstetric population in a general hospital during the 1980 s.

\section{Patients and methods}

The study was performed between 1 October 1982 and 31 March 1984 on consecutive patients attending the antenatal clinics of this hospital, which serves an almost exclusively white mixed urban and semirural population. The obstetric population was unselected and attendance was based on geographical rather than medical criteria. Nearly all patients received their antenatal care jointly from the hospital and their family doctor, with most women attending the hospital clinic four or five times during the pregnancy. The few high risk pregnancies were seen more often at the hospital clinic. Six antenatal clinics were held each week.

On their first visit, which occurred at 12.6 (SD 3.6) weeks' gestation, women were given a questionnaire, which was completed before leaving.

\footnotetext{
University Department of Materia Medica, Stobhill General Hospital, Glasgow G21 3UW

PETER C RUBIN, DM, MRCP, Wellcome Trust senior fellow in clinical science GILLIAN F CRAIG, research assistant

KAREN GAVIN, research assistant

DAVID SUMNER, DPHIL, honorary lecturer

Correspondence to: Dr Rubin.
}

The questions identified gestation, cigarette smoking, alcohol consumption, social class, medical conditions, drugs taken since the last menstrual period, and source of drugs. It was explained to each woman that the questionnaire was confidential and would not form part of the medical record. One of us (KG) attended each clinic, ensured distribution and collection of forms, and assisted with completion of the questionnaire if necessary. In cases when a woman could not recall the name of a drug her family doctor was contacted or hospital record consulted for further information. This was necessary in $290(10.5 \%)$ cases. At subsequent visits women were given a similar questionnaire asking for details of drugs used since the last attendance. Collection of data ended with the last visit to the clinic: drugs used during delivery and in the puerperium were not recorded. To assess the accuracy of the information obtained, the family doctor of every 10th woman was asked to provide information on drugs prescribed between the last menstrual period and the date of delivery. Replies were obtained for 250 of the 276 patients and indicated $84 \cdot 2 \%$ agreement between what the patients claimed to have taken and information given by their doctors. The under-representation was accounted for largely by antibacterial and antiemetic drugs. Of the women approached, $216(7 \cdot 8 \%)$ refused to participate in the study.

For the purposes of this study supplements of iron and vitamins are not recorded as drugs, although their use was included in the analysis of outcome of pregnancy that was subsequently performed. Also excluded from the study were women attending the separate clinic for hypertension in pregnancy. There is a strong local interest in hypertension, many women being part of clinical trials, and their inclusion would have given a false view of the use of drugs in an obstetric population in a general hospital. The women recorded as receiving an antihypertensive drug, therefore, were only those who began treatment with either their obstetrician or family doctor

Data were coded numerically and stored on the University of Glasgow ICL 2988 computer, with identification of patients by hospital number to retain confidentiality. Analysis was performed using the biomedical data package (BMDP). ${ }^{8}$ Use of drugs was analysed by both individual agents and groups of drugs using the classification adopted by the British National Formulary. ${ }^{9}$ Details on outcome of pregnancy were collected separately and will be presented subsequently. Statistical analysis was by $\chi^{2}$ test.

The ethics committee of the Greater Glasgow Health Board, northern district, considered that no ethical problems were presented in the study and that a consent form was not necessary.

\section{Results}

The study concerned 2765 women, of whom $2579(93 \cdot 3 \%)$ avoided exposure to drugs in the first trimester and $1802(65 \cdot 2 \%)$ took no drug at any stage of pregnancy. The remaining $963(34 \cdot 8 \%)$ took a total of 154 different drugs from 35 groups.

Table I shows the distribution of social class for the whole group and by exposure to drugs. There was a significant difference in distribution of social

TABLE I-Social class of study population

\begin{tabular}{|c|c|c|c|c|c|c|c|}
\hline & \multicolumn{5}{|c|}{ Social class } & \multirow[b]{2}{*}{ Unemployed } & \multirow{2}{*}{$\begin{array}{l}\text { No trace of } \\
\text { occupation }\end{array}$} \\
\hline & I & II & III & IV & $\mathbf{V}$ & & \\
\hline $\begin{array}{l}\text { All women } \\
\text { Non-drug takers } \\
\text { Drug takers }\end{array}$ & $\begin{array}{l}88 \\
48 \\
40\end{array}$ & $\begin{array}{l}450 \\
243 \\
207\end{array}$ & $\begin{array}{r}1160 \\
750 \\
410\end{array}$ & $\begin{array}{l}366 \\
244 \\
122\end{array}$ & $\begin{array}{r}133 \\
93 \\
40\end{array}$ & $\begin{array}{l}443 \\
324 \\
119\end{array}$ & $\begin{array}{r}125 \\
100 \\
25\end{array}$ \\
\hline
\end{tabular}

class between takers and non-takers of drugs $(p<0.001)$, which was the result of higher social classes being over-represented and unemployed people under-represented in the groups taking drugs. Table II gives distributions for cigarette smoking and table III for alcohol consumption. There was no relation between cigarette smoking and use of drugs, but 
TABLE II-Number of cigarettes smoked each day during pregnancy

\begin{tabular}{lrccc}
\hline & 0 & $1-10$ & $11-20$ & $>20$ \\
\hline All women & 1812 & 429 & 434 & 90 \\
Non-drug takers & 1178 & 296 & 275 & 53 \\
Drug takers & 634 & 133 & 159 & 37 \\
Edinburgh & 392 & 264 & 237 & 18 \\
\hline
\end{tabular}

TABLE III-Alcohol consumption during pregnancy

\begin{tabular}{lcccc}
\hline & No alcohol & $\begin{array}{c}\text { Occasional } \\
\text { drinking }\end{array}$ & $\begin{array}{c}\text { Moderate } \\
\text { drinking }\end{array}$ & $\begin{array}{c}\text { Heavy } \\
\text { drinking }\end{array}$ \\
\hline All women & 1786 & 925 & 53 & 1 \\
Non-drug takers & 1219 & 558 & 25 & 1 \\
Drug takers & 567 & 367 & 28 & 128 \\
Edinburgh study & 109 & 392 & 282 & \\
\hline
\end{tabular}

TABLE IV-Comparison of use of drugs during pregnancy in study in Glasgow 1982-4 $(n=2765)$ and in Edinburgh 1963-5 $(n=911)$

\begin{tabular}{lcc}
\hline Drugs & $\begin{array}{c}\text { No (\%) of cases in } \\
\text { Edinburgh 1963-5 }\end{array}$ & $\begin{array}{c}\text { No (\%) of cases in } \\
\text { Glasgow 1982-4 }\end{array}$ \\
\hline All non-narcotic analgesics & $574(63)$ & $357(12 \cdot 9)$ \\
Self administered non-narcotic analgesics & $437(48)$ & $174(6 \cdot 3)$ \\
Barbiturates & $255(28)$ & $4(0 \cdot 25)$ \\
Anxiolytics/sedatives/hypnotics & $45(5)$ & $55(2)$ \\
Antibacterials & $255(28)$ & $284(10 \cdot 3)$ \\
Antiemetics & $209(23)$ & $152(5 \cdot 5)$ \\
Antacids & $574(63)$ & $205(7 \cdot 4)$ \\
Diuretics & $164(18)$ & $5(0 \cdot 2)$ \\
\hline
\end{tabular}

TABLE V-Comparison of use of drugs during first trimester in study in Glasgow 1982-4 $(n=2765)$ and in Edinburgh 1963-5 $(n=911)$

\begin{tabular}{lcc}
\hline Drugs & $\begin{array}{c}\text { No (\%) of cases in } \\
\text { Edinburgh 1963-5 }\end{array}$ & $\begin{array}{c}\text { No (\%) of cases in } \\
\text { Glasgow 1982-4 }\end{array}$ \\
\hline Non-narcotic analgesics & $73(8)$ & $81(2 \cdot 9)$ \\
Barbiturates & $45(5)$ & $2(0 \cdot 07)$ \\
Anxiolytics/sedatives/hypnotics & $18(2)$ & $7(0 \cdot 2)$ \\
Antibacterials & $82(9)$ & $38(1 \cdot 4)$ \\
Antiemetics & $118(13)$ & $22(0 \cdot 8)$ \\
Antacids & $27(3)$ & $13(0 \cdot 5)$ \\
Appetite suppressants & $9(1)$ & \\
\hline
\end{tabular}

women who did not take a drug during pregnancy showed a small but significant $(\mathrm{p}<0.001)$ trend towards lower alcohol consumption.

The 10 most commonly used groups of drugs were: non-narcotic analgesics $357(12 \cdot 9 \%)$ cases, antibacterials 284 (10.3\%), antacids 205 $(7 \cdot 4 \%)$, antinauseants $152(5 \cdot 5 \%)$, cough medicines including antitussive, expectorant, and mucolytic drugs $88(3 \cdot 2 \%)$, anxiolytics/sedatives/hypnotics $55(2 \%), \beta$ blockers $27(1 \%)$, stimulant laxatives $24(0.9 \%)$, anticonvulsants $22(0.8 \%)$, and bronchodilator inhalers $20(0.7 \%)$. Those groups of drugs used most often in the first trimester were: non-narcotic analgesics 81 $(2 \cdot 9 \%)$, antibacterials $38(1 \cdot 4 \%)$, antinauseants $36(1 \cdot 3 \%)$, antacids 13 $(0.5 \%)$, cough medicines $13(0.5 \%)$, stimulant laxatives $10(0.3 \%)$, endocrine preparations $8(0.3 \%)$, anxiolytics/sedatives/hypnotics $7(0.2 \%)$, narcotic analgesics $6(0 \cdot 2 \%)$, and bronchodilator inhalers $4(0 \cdot 1 \%)$. Most analgesics $(221(61.9 \%))$ were self administered while both antacids (161 $(78.5 \%))$ and antiemetics $(138(90 \cdot 8 \%))$ were usually obtained by prescription from the family doctor.

Several aspects of this study can be compared with the findings of the last survey of use of drugs during pregnancy in the United Kingdom, which was performed in Edinburgh in 1963-5 and included 911 women. The patterns of cigarette smoking and alcohol consumption in this study are also shown in tables II and III, respectively. A significant reduction in both cigarette smoking and alcohol consumption was evident $(p<0.001)$. While complete abstinence from alcohol had increased fivefold, however, non-smoking had increased by only a half. The proportion of women who did not take a drug during pregnancy rose from $195(21 \cdot 4 \%)$ in the earlier study to $1802(65 \cdot 2 \%)$ in this survey $(p<0.001)$. Those avoiding drugs in the first trimester increased from $685(75 \cdot 2 \%)$ to $2588(93.6 \%)(p<0.001)$. A self administered drug was used at some stage during pregnancy by $586(64.4 \%)$ women in the previous study compared with only $243(8.8 \%)$ in the recent one $(p<0.001)$. In the first trimester use of self administered drugs changed from $31(3.4 \%)$ cases 20 years ago to $53(1.9 \%)$ cases $(p<0.02)$. Table IV shows the relative exposure to the most commonly used groups of drugs during the whole of pregnancy, and table $\mathrm{V}$ shows those used during the first trimester. In all cases there was a substantial reduction in use of drugs over 20 years.

\section{Discussion}

Our aim was to perform a study that was sufficiently large to draw valid conclusions but in which high quality collection of data could be assured. We therefore used a simple questionnaire that occupied only one side of paper and depended on a recall of information over at most a few weeks; and we collected all the data before the outcome of pregnancy was known. There was a high level of agreement between drugs that the women said had been prescribed by their family doctor and those that the doctors themselves had recorded as prescribed. At most, the results of this survey seem to have underestimated the use of drugs by nearly $16 \%$, a proportion that would not influence the findings. The underestimated value could, however, be less than this if prescribed drugs had not actually been taken.

Most women did not take a drug, particularly during the first trimester, but a substantial minority took a non-narcotic analgesic, an antibacterial drug, an antacid, or an antiemetic agent at some stage in the pregnancy. The use of non-narcotic analgesics is noteworthy as their safety in pregnancy is uncertain. There have been several reports suggesting an association between exposure to aspirin and fetal malformation, ${ }^{10-12}$ although another study suggested that aspirin was not teratogenic. ${ }^{13}$ Aspirin has also been implicated in an increased perinatal mortality, ${ }^{14}$ impaired neonatal haemostasis, ${ }^{15}$ and pulmonary hypertension in the neonate. ${ }^{16}$ There have been no extensive studies of paracetamol during pregnancy. When uncertainty exists concerning safety in pregnancy it seems wiser to avoid the drugs concerned. Most analgesics, however, were self administered, and a change in the pattern of use of drugs would require carefully balanced information on health education.

Antiemetics were used by $152(5 \cdot 5 \%)$ women at some stage during pregnancy and by only $36(1 \cdot 3 \%)$ during the first trimester. This remarkably low rate of usage almost certainly reflects two factors: firstly, during the study considerable attention was paid by the media to the claims that antiemetics could be teratogenic, and, secondly, Debendox (Bendectin) was effectively withdrawn from the market in June 1983, nine months after the survey began.

The last survey of use of drugs in pregnancy in the United Kingdom was performed 20 years ago in Edinburgh. ${ }^{4}$ Important differences in the methods of the studies-for example, the Edinburgh study was retrospective and did not record social class-limit the possibility of making precise comparisons. Both studies, however, were performed in mixed urban and semirural populations of major Scottish cities, and in each case considerable attention was paid to ensuring the quality of collecting data. There has been a general reduction in the use of all groups of drugs but particularly antiemetics during the first trimester and barbiturates and diuretics during the whole of pregnancy (see tables IV and V). The special factors concerned with the use of antiemetics have already been mentioned. Barbiturates were used during the Edinburgh survey primarily as anxiolytic agents, and the dramatic reduction in use reflects a general prescribing trend away from these drugs. The only women receiving a barbiturate in the Glasgow study were taking phenobarbitone for epilepsy. Diuretics were used in the Edinburgh study primarily for the treatment of oedema (not hypertension), and again there has been a strong trend away from this approach. There are interesting differences between the two studies with regard to cigarette smoking and alcohol consumption. There has been a substantial reduction in alcohol consumption; most women now abstain completely from alcohol throughout pregnancy (see table III). By contrast, although more women are now non-smokers than was the case 20 years ago, the trend is far less dramatic than that for alcohol consumption (see table II). In addition, the number of women who smoked during pregnancy (954 $(34.5 \%)$ ) was similar to that of young women who smoked in the 
west of Scotland (Scottish Committee Action on Smoking and Health, personal communication). There are two likely reasons for this difference: firstly, the habit forming nature of cigarette smoking probably makes it easier for the average person to stop drinking rather than to stop smoking, and, secondly, the risks of the fetal alcohol syndrome have been widely publicised, particularly in the west of Scotland.

Little is known about clinical pharmacology during pregnancy. A survey of this type can identify those drugs that are most commonly used, highlighting where further research into safety and efficacy might appropriately be pursued. The limited available knowledge on the disposition of drugs during pregnancy indicates that in some instances, such as the use of anticonvulsants, substantial and clinically important changes require an approach to prescribing quite different from that in non-obstetric practice. A knowledge of those drugs most often used allows direction of research into clinical pharmacokinetics during pregnancy. There is virtually no available information on whether pregnancy influences the effect of drugs, and yet a typical obstetric unit can expect to see an average of two new patients each week who are receiving a drug such as a bronchodilator, $\beta$ blocker, or anticonvulsant, the effect of which could, theoretically, be influenced by the physiological changes of pregnancy. An additional point to emerge from studies of this type is the question of whether the drugs used were really necessary. This, of course, is a matter not confined to pregnancy, but the lists given earlier suggest that the mother's health would not have been put at risk if some of the more commonly used groups of drugs were withheld.

In conclusion, we have described the pattern of use of drugs in a general obstetric unit in Glasgow during the mid-1980s. Most women did not take drugs or drink alcohol, but the extent of cigarette smoking, the use of self administered analgesics, and the relatively common administration of drugs clearly not necessary for maternal health are matters worthy of further attention.

We thank Dr C J Bulpitt for advice in planning these studies, Dr M De Swiet for critical review of the manuscript, and the obstetricians at this hospital for allowing us to study their patients.

\section{References}

1 Mellin GW, Katzenstein M. The saga of thalidomide. N Engl f Med 1962;267:1184-92, 1238-44. 2 Hayman DJ. Withdrawal of thalidomide. BrMed $\mathcal{F} 1961$; iv: 1499

Kullander S, Kallen B. A prospective study of drugs and pregnancy. Acta Obstet Gynecol Scand 1976;55:287-95.

4 Forfar JO, Nelson MM. Epidemiology of drugs taken by pregnant women: drugs that may affect the fetus adversely. Clin Pharmacol Ther 1973;14:632-42.

5 Peckham $\mathrm{CH}$, King RW. A study of intercurrent conditions observed during pregnancy. $A m \mathcal{F}$ Obstet Gynecol 1963;87:609-20.

6 Heinonen OP, Slone D, Shapiro S. Birth defects and drugs in pregnancy. Littleton, Massachusetts: Publishing Sciences Group, 1977.

7 Brocklebank JC, Ray WA, Federspiel CF, Schaffner W. Drug prescribing during pregnancy. Am f Obstet Gynecol 1978;132:235-44

8 Dixon WJ, ed. BMDP statistical software. California: University of California Press, 1983

8 Dixon WJ, ed. BMDP statistical software. California: University of California Press, 1983. formulary No 9. London: British Medical Association and the Pharmaceutical Society of Great formulary No 9. London: British Medical Association and the Pharmaceutical Society of Great

10 Nelson MM, Forfar JO. Association between drugs administered during pregnancy and congenital abnormalities of the fetus. Br Med f 1971;i:523-7.

$11 \mathrm{McNeil}$ JR. The possible teratogenic effect of salicylates on the developing fetus. Clin Pediatr (Phila) 1973;12:347-50.

12 Richards ID. Congenital malformations and environmental influences in pregnancy. Brf Prev Soc Med 1969;23:218-25.

13 Slone D, Suskind V, Heinonen OP. Aspirin and congenital malformations. Lancet 1976;i:1373-5. 14 Turner G, Collins E. Fetal effects of regular salicylate ingestion in pregnancy. Lancet 1975;ii: 338-9.

15 Stuart MJ, Gross SJ, Elrad H, Graeber JE. Effects of acetylsalicylic acid ingestion on maternal and neonatal hemostasis. N Engl f Med 1982;307:909-12.

16 Perkin RM, Levin D, Clark D. Serum salicylate levels and right to left ductus shunt in newborn infants with persistent pulmonary hypertension. $\mathcal{F}$ Pediatr 1980;96:721-6.

\title{
Intermittent clinical proteinuria and renal function in diabetes: evolution and the effect of glycaemic control
}

\author{
J J BENDIIJG，G C VIBERTI，P J WATKINS， H KEEN
}

\begin{abstract}
The evolution of renal disease was studied in 12 insulin dependent diabetics selected for intermittent clinical proteinuria. After a run in period during which patients were studied three monthly for at least 12 months members of pairs of patients matched for age and duration of diabetes were allocated either to receive continuous subcutaneous insulin infusion or to continue with their usual conventional insulin injection therapy (controls) and studied three monthly for a further year. Mean (SEM) plasma glucose concentration and glycosylated haemoglobin $\left(\mathbf{H b A}_{1}\right)$ value improved significantly in the insulin infusion group (glucose 10.1 (1.0) v 5.3(0.3) $\mathrm{mmol} / 1$ (182 (18) v $95(5) \mathrm{mg} / 100 \mathrm{ml}$ );
\end{abstract}

\footnotetext{
Unit for Metabolic Medicine, United Medical and Dental Schools (Guy's Campus), London SE1 9RT

J J BENDING, MD, MRCP, Wolfson research fellow and honorary senior registrar GC VIBERTI, MD, MRCP, senior lecturer and honorary consultant

H KEEN, MD, FRCP, professor of human metabolism
}

Diabetic Clinic, King's College Hospital, London SE5 9RS

P J WATKINS, MD, FRCP, consultant physician

Correspondence and requests for reprints to: Dr Viberti.
$\mathrm{HbA}_{1} 9.6(0.8) v 7.6(0.5) \% ; \mathbf{p}<0.001$ and $\mathbf{p}<0.005$, run in $v$ experimental periods) but not in the control group. Blood pressure was kept normal throughout.

Glomerular filtration rate fell significantly in the insulin infusion and control groups throughout the study, from mean (SEM) baseline values of $114(16)$ and $119(15) \mathrm{ml} / \mathrm{min} / 1.73 \mathrm{~m}^{2}$ to final values of $92(15)$ and $95(13) \mathrm{ml} / \mathrm{min} / 1.73 \mathrm{~m}^{2}$ respectively $(p<0.05$ and $p<0.01)$. The mean rate of decline in glomerular filtration rate did not change significantly in either group (run in $v$ experimental periods: insulin infusion group $1.0 v 0.8 \mathrm{ml} / \mathrm{min} /$ month; controls $0.8 v 0.9 \mathrm{ml} / \mathrm{min} /$ month). Mean (SEM) plasma creatinine concentration rose slightly in the insulin infusion group only (93 (5) to $107(11) \mu \mathrm{mol} / 1(1.1(0.06)$ to $1.2(0.1) \mathrm{mg} /$ $100 \mathrm{ml}), 0.1>$ p $>0.05$; controls $94(6)$ to $96(6) \mu \mathrm{mol} / 1(1.1(0.07)$ and $1.1(0.07) \mathrm{mg} / 100 \mathrm{ml})$ ). The urinary excretion rate of albumin varied widely and unpredictably throughout, while $\beta_{2}$ microglobulin excretion remained normal and unchanged in both groups.

Thus (a) at the stage of intermittent clinical proteinuria when albumin excretion rate is unpredictably variable (breaking through the "clinically positive" threshold only episodically) renal function, though still in the "normal" range, is already declining progressively; and (b) the study failed to show that sustained improvement in mean glycaemia exerts a significant effect on this early deterioration of renal function. 